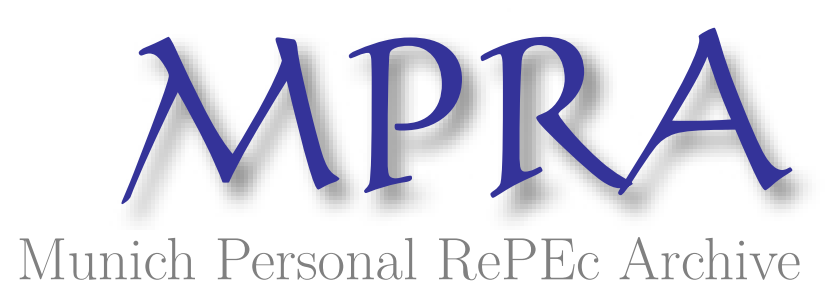

\title{
Kuznets meets Lucas: Structural Change and Human Capital
}

\author{
Cruz, Edgar \\ University of Guanajuato
}

28 July 2018

Online at https://mpra.ub.uni-muenchen.de/88246/

MPRA Paper No. 88246, posted 31 Jul 2018 03:44 UTC 


\title{
Kuznets meets Lucas: Structural Change and Human Capital* $^{*}$
}

\author{
Edgar Cruz \\ Department of Economics and Finance \\ University of Guanajuato
}

July 28, 2018

\begin{abstract}
This paper develops a multi-sector growth model with human capital accumulation. In this model, human capital induces structural change through two channels: changes in relative prices and changes in the investment rate of physical and human capital. We show that the specifications of the model give rise to a generalized balanced growth path. Furthermore, we show that the model is consistent with (i) the decline in agriculture, (ii) the hump-shaped of manufacturing, (iii) the rise of the services sector and (iv) the path of human capital accumulation in the U.S economy during the twenty century. Given our findings, we outline that imbalances between physical and human capital contribute to explain cross-country differences in the pace of structural change.
\end{abstract}

JEL classification codes: 041, 047.

Keywords: Human capital; Structural change; Economic growth

${ }^{*}$ I thank Xavier Raurich, for his helpful suggestions. I am grateful to Akos Valentinyi, Marc Teignier, Marti Mestieri, and Miguel Leon-Ledesma for valuable comments and suggestions. I acknowledge financial support from the Universitat de Barcelona through the grant APIF and CONACYT through the grant 383793. Address: University of Guanajuato. Department of Economics and Finance, 4th floor. Fraccionamiento 1; Col. El Establo S/N; C.P. 36250. Guanajuato, Mexico. E-mail: be.cruz@ugto.mx 


\section{Introduction}

In the current literature on structural change and economic growth, there are two explanations for the shift from agriculture to non-agriculture activities, the so-called Kuznets facts. The first explanation emphasizes the role of changes in the composition of the demand on structural change. These changes are based on the Engel law: as income rises, demand for agricultural goods decreases as well as the share of agriculture in GDP due to the agricultural goods has the lower income elasticity (see Kongsamut, Rebelo and Xie, 2001; Meckl, 2002; Foellmi and Zweimüller, 2008; Boppart, 2014). The second explanation relies on technological differences across sectors. In this branch of the literature, sectoral differences in rates of technological progress or capital intensity explain structural change. In Ngai and Pissarides (2007), labor moves from the productive sectors (those with the highest productivity growth) to the stagnant sectors (those with the lowest productivity growth), whereas, in Acemoglu and Guerrieri (2008), labor moves from the more capital-intensive sectors to the less capital-intensive sectors. Interestingly, while these demand and supply factors explain the Kuznets facts in the framework of multisectoral growth models, both mechanisms rely on growth models where technological progress is exogenous. ${ }^{1} \mathrm{We}$ contribute to this literature by building a continuous-time model of economic growth that encompasses the technological-explanation of the Kuznets facts with endogenous technological progress.

To this end, we consider a four-sector version of the endogenous growth model introduced by Lucas (1988). Firms in three sectors produce goods that are devoted to consumption or investment. We identify these sectors as the agriculture, manufacturing and services sectors. Firms in the fourth sector, which we define as the educational sector, produce a good that is devoted only to increase the stock of human capital. Whereas firms in the educational sector produce using only the time that individuals devote to education, we assume that firms in the non-educational sector produce consumption goods by combining physical and human capital. As in the Lucas' model, we also assume that the economy-wide average human capital causes an externality in the non-educational sectors. Explicitly, we assume sector specific strengths of the externality.

In this model, human capital accumulation drives structural change through two channels. In the first channel, human capital accumulation causes endogenous sectoral technical progress. The differences in the rate of technical progress across sectors arise due to sector-specific strengths of the externality. As occurs in Ngai and Pissarides (2007), these differences in productivity growth rates across sectors induce changes in relative prices, which cause structural change. ${ }^{2}$ We show that the empirical

\footnotetext{
${ }^{1}$ See Herrendorf, Rogerson, and Valentinyi (2014) for a review of the empirical evidence on the dynamics of the sectoral composition in developed countries as well as a thorough review of the theoretical explanations of structural change in the economic literature.

${ }^{2}$ Empirical evidence suggests that the observed changes in sectoral relative prices are due to change in technological progress at the sectoral level. For instance, Alvarez-Cuadrado and Poschke (2011) analyze available data for the relative prices of farm and non-farm goods for 11 advanced countries over the last two centuries. They find that changes in relative prices are related to changes in the bias of sectoral technological progress. Moreover, Duarte and Restuccia (2010) show that movement in sectoral productivity mainly explains changes in relative prices in the U.S economy in the period 1971-2004.
} 
relevant case occurs when external effects are higher in the agriculture sector than in manufacturing and services sectors. In this case, the relative price of agriculture goods decreases and induces labor to move toward the service sector. We refer to this channel as the endogenous price effect on structural change.

In the second channel, the initial stocks of human and physical capital cause structural change. In the model, individuals choose between investing in human and physical capital. If the initial ratio between this two stocks of capital differs from its long-run value, individuals decide either to allocate more employment into the education sector or to allocate employment in the manufacturing sector to accumulate more physical capital. We refer to this channel as the endogenous investment effect on structural change.

Under these specifications, we show that the model can give rise to a balanced growth path along which structural change occurs. We show that investment channel affects structural change only during the transition to the balanced growth path, whereas sectoral technical progress continues driving structural change at the equilibrium. We use this model to analyze the effects of these two channels on structural change and investigate their implications for development. To this end, we propose two numerical exercises. In the first one, we analyze the accuracy of this model in explaining observed patterns of structural change in the United States along the 20th century, a period characterized by a rapid accumulation of human capital. In the second exercise, we extend the numerical analysis to outline the role of imbalances between physical and human capital in explaining cross-country differences in the sectoral composition of the economy and the pace of structural change.

Our numerical exercises show that the model is capable of explaining (i) the hump-shaped pattern in of the manufacturing sector and (ii) the secular trend in human capital accumulation along the 20th century. Furthermore, we found that the imbalance between physical and human capital can explain cross-country differences in both the sectoral composition and the pace of structural change. We conclude that human capital is an essential factor explaining not only economic growth but also crosscountry differences in sectoral composition.

The paper is organized as follows. Section 2 presents the basic model. Section 3 characterizes the equilibrium dynamics. Section 4 develops the numerical analysis. Section 5 presents some concluding remarks, while the appendices contain the proofs of all the results of the paper.

\section{The model}

We assume that the economy is populated by a single infinitely lived representative agent,which obtains utility from the consumption of goods. These goods are produce in three sectors. The first sector produces a good that can be consumed or invested in physical capital. We refer to this sector as the manufacturing sector, and we denote it by using the sub-index $m$. The second and third sectors produce only goods devoted to consumption. We refer to these sectors as agriculture and services sectors denoted by the sub-indexes $a$ and $s$, respectively. Finally, the fourth sector produces a good that is exclusively devoted to increasing the stock of human capital. We refer to this sector as the education sector, and we denote it by using the sub-index $h$. 


\subsection{Preferences}

We assume that the economy is populated by a single infinitely lived representative agent, which obtains utility from the consumption of services $\left(c_{s}\right)$, agricultural $\left(c_{a}\right)$ and manufacturing $\left(c_{m}\right)$ goods. In particular, we assume that the instantaneous utility function is

$$
u=\ln \tilde{c},
$$

where $\tilde{c}$ denotes the composite consumption good. This good satisfies

$$
\tilde{c}=\left(\eta_{a} c_{a}^{\frac{\epsilon-1}{\epsilon}}+\eta_{m} c_{m}^{\frac{\epsilon-1}{\epsilon}}+\eta_{s} c_{s}^{\frac{\epsilon-1}{\epsilon}}\right)^{\frac{\epsilon}{\epsilon-1}}
$$

where $\epsilon$ is the elasticity of substitution between the three goods, $\eta_{a}, \eta_{m}$, and $\eta_{s}$ measure the weights of sectoral consumptions in utility. These weights satisfy $\eta_{m}+\eta_{s}+\eta_{a}=$ 1. Following Ngai and Pissarides (2007), we have assumed that the intertemporal elasticity of substitution for the composite good $\tilde{c}$ is equal to one and the elasticity of substitution between the three goods is $\epsilon<1$. The first assumption ensures existence of a Generalized Balanced Growth Path (henceforth, GBGP). A GBGP is defined as an equilibrium path in which the interest rate remains constant and aggregate physical capital and total consumption expenditure grow at a constant rate but shifts in industrial employment shares occurs. ${ }^{3}$ The second assumption implies that goods are complements, which is a necessary condition to explain the observed patterns of structural change in a model with homothetic preferences as Ngai and Pissarides (2007) pointed out.

The representative agent is endowed with $k$ units of physical capital and $h$ units of human capital, which supply to firms together with her labor endowment of measure one. Thus, the representative agent chooses her consumption of goods and service, and investment in both physical and human capital, as well as the sector in which she rents the inputs she owns. We assume perfect sectoral mobility of inputs, which implies that wage and interest rate are equal across sectors. Consequently, the budget constraint of the consumer is given by

$$
w h+r k=p_{s} c_{s}+p_{a} c_{a}+p_{m} c_{m}+p_{m} I_{k}+p_{h} I_{h},
$$

where $w$ is the wage rate and $r$ is the interest rate; $p_{s}, p_{a}, p_{m}$ and $p_{h}$ are the relative prices of services, agriculture and manufacturing goods, and human capital; $I_{h}$ and $I_{k}$ are the gross investment in human and physical capital, respectively, and thus ${ }^{4}$

$$
\begin{aligned}
& I_{k}=\dot{k}+\delta k, \\
& I_{h}=\dot{h} .
\end{aligned}
$$

The optimization problem of the representative agent consists on choosing $\left\{c_{s}, c_{a}, c_{m}, I_{k}, I_{h}\right\}$ to maximize the discounted sum of utilities (2.1) subject to (2.3),

\footnotetext{
${ }^{3}$ Logarithm preferences ensure that the growth rate of total consumption expenditure does not depend on changes in relative prices.

${ }^{4}$ As in Lucas (1988), we assume that there is not depreciation of human capital.
} 
(2.4), (2.5) and given initial $k_{0}$ and $h_{0}$. The solution of this maximization problem is characterized by the following equations ${ }^{5}$

$$
\begin{aligned}
& \frac{p_{a} c_{a}}{c}=\sigma_{a}, \\
& \frac{p_{s} c_{s}}{c}=\sigma_{s},
\end{aligned}
$$

and

$$
\frac{\dot{c}_{m}}{c_{m}}=r-\rho-\delta-(1-\epsilon) \sum_{i=a, s} \sigma_{i} \frac{\dot{p}_{i}}{p_{i}}
$$

where

$$
\sigma_{i}=\frac{\bar{\eta}_{i} p_{i}^{1-\epsilon}}{1+\sum \bar{\eta}_{i} p_{i}^{1-\epsilon}}
$$

$c=p_{a} c_{a}+p_{m} c_{m}+p_{s} c_{s}$ is the total consumption expenditure, and $\bar{\eta}_{i}=\left(\eta_{i} / \eta_{m}\right)^{\epsilon}>0$ for $i=a, s$. Equations (2.6) and (2.7) characterize the sectoral composition of consumption expenditures, while (2.8) is the Euler condition driving the intertemporal trade-off between consuming manufacturing goods today and in the future. This equation equals the rate of return on investment in physical capital $(r)$ and the increase of marginal utility from consuming an additional unit of the manufacturing good. Given the structure of preferences, the marginal utility from consuming manufacturing goods depends on marginal changes in consumption of agricultural goods and services indicated in the summation term in (2.8).

\subsection{Firms}

In this economy, firms in agriculture, manufacturing, and services sectors are identical and produce consumption goods by combining physical and human capital. Following Ngai and Pissarides (2007), we assume that the physical capital's output elasticity is equal across sectors and they produce an amount of commodity $y_{i}$ by using the following production function:

$$
y_{i}=A_{i}\left(s_{i} k\right)^{\alpha}\left(u_{i} h\right)^{1-\alpha} \bar{h}^{\psi_{i}},
$$

where $s_{i}$ and $u_{i}$ are the shares of physical and human capital allocated in the sector i; $A_{i}$ stands for a sector-specific productivity level, which is constant over time; and $\alpha \in(0,1)$ is the physical capital's output elasticity. ${ }^{6}$ As in Lucas (1988), economy-wide average human capital $(\bar{h})$ generates externalities in production, but not in the human capital accumulation process. In equation (2.10), the parameter $\psi_{i} \geq 0$ measures

\footnotetext{
${ }^{5}$ Together with the transversality conditions $\lim _{t \rightarrow \infty}\left(e^{-\rho t} \mu_{2} k\right)=0$, and $\lim _{t \rightarrow \infty}\left(e^{-\rho t} \mu_{h} h\right)=0$, where $\mu_{2}$ and $\mu_{h}$ are the shadow prices of physical and human capital, respectively.

${ }^{6}$ Despite the fact that capital-intensive varies across sectors (Echevarría, 1997; Valentinyi and Herrendorf, 2008), we assume that there are not sectoral differences in capital intensive to focus on the effects of human capital on sectoral productivities. As a result, we exclude from the model capital deepening (see Acemoglu and Guerrieri, 2008). Dennis and Iscan (2009) show that the effect of capitaldeepening on structural change in U.S. economy is marginal and complementary to the biased technical change. Moreover, Herrendorf, Herrington, and Valentinyi (2015) found that a Cobb-Douglas production functions that differ only in technical progress capture the main trend in the postwar US structural change.
} 
the elasticity of output with respect to the aggregate external effect of human capital. Given the assumptions on the production function, total factor productivity (TFP) across sectors is defined by $A_{i} \bar{h}^{\psi_{i}}$. This implies that the differences in rates of sectoral technical progress across sectors are driven only by differences in the strength of productive externalities across sectors. We identify these sectors as the non-educational segment of the economy.

In the educational sector, firms are identical and produce $y_{h}$ using only human capital as an input. For the sake of simplicity, we assume that the production function is a linear function of form

$$
y_{h}=B u_{h} h
$$

where $B>0$ is a constant which stands for a productivity level, and $u_{h}$ is the share of human capital allocated in the educational sector. We assume the commodity $y_{h}$ is devoted exclusively to increase the stock of human capital, while $y_{m}$ is the only commodity that can be either consumed or added to the stock of physical aggregate capital.

The optimization problem of competitive firms in the non-educational sectors consists on choosing the amount of physical and human capital without taking into account the effect of average human capital to maximize their profits, while in the educational sectors competitive firms' problem consists on choosing only the amount of human capital to maximize their profits. ${ }^{7}$

Perfect competition and perfect factors' mobility imply that each factor is paid according to its marginal productivity and that marginal productivities equalize across sectors, implying that the interest rate is

$$
r=p_{i} \alpha A_{i}\left(s_{i} k\right)^{\alpha-1}\left(u_{i} h\right)^{1-\alpha} \bar{h}^{\psi_{i}}
$$

and the wage rate is

$$
w=p_{i}(1-\alpha) A_{i}\left(s_{i} k\right)^{\alpha}\left(u_{i} h\right)^{-\alpha} \bar{h}^{\psi_{i}}
$$

where $p_{i}$ is the relative price. We assume that the commodity produced in the goods sector is the numeraire and, hence, $p_{m}=1$. From using (2.12) and (2.13), we obtain that the optimal physical capital shares must satisfy

$$
s_{i} u_{m}=s_{m} u_{i},
$$

the relative prices of services and agricultural goods are

$$
p_{i}=\left(\frac{A_{m}}{A_{i}}\right) h^{\psi_{m}-\psi_{i}}
$$

and the relative price of human capital is

$$
p_{h}=\frac{w}{B} \text {. }
$$

Note that the growth rate of relative prices depends on the growth rate of human capital according to the following equation:

$$
\frac{\dot{p}_{i}}{p_{i}}=\left(\psi_{m}-\psi_{i}\right) \frac{\dot{h}}{h}, i=a, s .
$$

\footnotetext{
${ }^{7}$ The solution to the firms's problem is derived in Appendix A.
} 
According to (2.17), the growth rate of relative prices of agriculture and services may be positive or negative. This result depends on the difference between the intensity of the externalities in these sectors and the manufacturing sector, and the sign of the growth rate of human capital. Empirical evidence shows that the price of agriculture goods decreases, whereas the price of services increases. Thus, we assume that $\psi_{a}>\psi_{m}$ and $\psi_{m}>\psi_{s}$ so that the time path of relative prices are consistent with the empirical evidence given a positive growth rate of human capital.

\section{The equilibrium}

In this section, we define competitive equilibrium, and we obtain the system of differential equations that characterize the equilibrium dynamics. We use these equations to find the long-run equilibrium, and we study how human capital accumulation modifies the sectoral composition during the transition and along the GBGP.

A competitive equilibrium in this economy, given the initial stocks of physical $\left(k_{0}\right)$ and human capital $\left(h_{0}\right)$, consists of a set of prices $\left\{r, w, p_{a}, p_{s}, p_{h}\right\}$ and quantities $\left\{y_{a}, y_{m}, y_{s}, y_{h}, c_{a}, c_{m}, c_{s}, I_{k}, I_{h}, u_{a}, u_{m}, u_{s}, u_{h}, s_{a}, s_{m}, s_{s}\right\}$ that satisfy the consumer and firms optimization conditions; the market clearing conditions (i) $\sum_{i=a, s, m} s_{i}=1$, (ii) $\sum_{i=a, s, m, h} u_{i}=1$, (iii) $y_{a}=c_{a}$ and $y_{s}=c_{s}$, (iv) $y_{m}=c_{m}+I_{k}$ and $y_{h}=I_{h}$; the equilibrium condition $h=\bar{h}$ together with the transversality conditions. ${ }^{8}$

From using (2.14) and the market clearing condition (i), we obtain that the optimal physical capital shares are

$$
s_{i}=\frac{u_{i}}{u_{a}+u_{m}+u_{s}}, i=a, m, s
$$

and using (2.15) and the equilibrium condition $h=\bar{h}$, we obtain that the interest rate is

$$
r=\alpha A_{m} k^{\alpha-1} h^{1-\alpha+\psi_{m}}\left(u_{a}+u_{m}+u_{s}\right)^{1-\alpha} .
$$

In order to characterize the equilibrium dynamics, we first define the aggregate output and the total consumption expenditure in our economy. $Q$ stands for the gross output of our economy (henceforth, GDP) and it is equal to

$$
Q=y+p_{h} y_{h},
$$

where $y=y_{m}+p_{s} y_{s}+p_{a} y_{a}$ is the sum of the value of output in the non-educational sectors, and $p_{h} y_{h}$ is the value, in units of manufacturing good, of the gross investment in human capital. By using (2.10), (2.15), the market clearing condition (iii), and (3.1), we obtain

$$
y=A_{m} k^{\alpha} h^{1-\alpha+\psi_{m}}\left(u_{m}+u_{a}+u_{s}\right)^{1-\alpha},
$$

and total consumption expenditure is

$$
c=\frac{c_{m}}{1-\sigma} .
$$

\footnotetext{
${ }^{8}$ Given that there is a representative household in the economy, the average stock of human capital coincides with the economy-wide stock of human capital as in Lucas (1988). In Appendix C, we show that the equilibrium satisfies the transversality conditions.
} 
where $\sigma=\sigma_{a}+\sigma_{s}$, and are defined in (2.9).

We then characterize the sectoral composition of the economy. To this end, we use (3.1) and the definitions in (3.3) and (3.4) to obtain that the optimal physical capital shares in agriculture, manufacturing, and services and the employment shares as functions of aggregate variables and relative prices. In the Appendix A, we show that physical capital shares given by

$$
\begin{aligned}
s_{m} & =1-\sigma \frac{c}{y}, \\
s_{i} & =\sigma_{i} \frac{c}{y},
\end{aligned}
$$

and the employment shares in agriculture, services and manufacturing sectors given by

$$
\begin{aligned}
u_{i} & =\left(\frac{1-\alpha}{\alpha} \frac{r k}{w h}\right)\left(\sigma_{i} \frac{c}{y}\right), \\
u_{m} & =\left(\frac{1-\alpha}{\alpha} \frac{r k}{w h}\right)\left(1-\sigma \frac{c}{y}\right) .
\end{aligned}
$$

Equations (3.7) and (3.8) implies that

$$
u_{a}+u_{m}+u_{s}=\frac{1-\alpha}{\alpha} \frac{r k}{w h} \equiv \chi
$$

where the variable $\chi$ stands for the total employment share in non-educational sectors. ${ }^{9}$

We now proceed to the characterization of the growth rate of total consumption expenditure and the two capital stocks. For that purpose, we take log-derivatives of (3.4), and using (2.8), (3.2), (3.7), (3.8), and (3.9), the growth rate of consumption expenditure is given by

$$
\frac{\dot{c}}{c}=\alpha A_{m} k^{\alpha-1} h^{1-\alpha+\psi_{m}} \chi^{1-\alpha}-\delta-\rho .
$$

where $\rho>0$ is the subjective discount rate. Equation (3.10) is the Euler condition that depends only on the interest rate. As explained in Ngai and Pissarides (2007), this result arises because we assume that the utility function is logarithmic in the consumption composite $\tilde{c}$, which implies an intertemporal elasticity of substitution equal to one. Thus, aggregate consumption expenditure is independent of changes in relative prices of agriculture and services.

We then use (2.4), (3.3), (3.4) and the market clearing condition (iv) to obtain the law of motion of physical capital

$$
\frac{\dot{k}}{k}=A_{m} k^{\alpha-1} h^{1-\alpha+\psi_{m}} \chi^{1-\alpha}-\frac{c}{k}-\delta
$$

and using (2.5) and the market clearing conditions (ii) and (iv), we obtain the the law of motion of human capital

$$
\frac{\dot{h}}{h}=B(1-\chi) .
$$

\footnotetext{
${ }^{9}$ Note that the total employment in non-educational sectors will depend on initial endowments of physical and human capital.
} 
We can now rewrite this economy equilibrium system in terms of the transformed variables. ${ }^{10}$ We use the variable $z$, that is defined as

$$
z=k h^{\frac{1-\alpha+\psi_{m}}{\alpha-1}},
$$

and we introduce one new transformed variable $q \equiv \frac{c}{k}$, which stands for the ratio between total consumption expenditure to aggregate physical capital. Thus, the law of motion of physical capital can be represented by

$$
\frac{\dot{k}}{k}=A_{m} z^{\alpha-1} \chi^{1-\alpha}-q-\delta
$$

and the Euler equation can be rewritten as

$$
\frac{\dot{c}}{c}=\alpha A_{m} z^{\alpha-1} \chi^{1-\alpha}-\delta-\rho .
$$

Finally, we obtain the growth rate of the transformed variables $z$ and $q$. By taking $\log$-derivatives in $q=c / k$, and using (3.14) and (3.15), the growth rate of $q$ is

$$
\frac{\dot{q}}{q}=(\alpha-1) A_{m} z^{\alpha-1} \chi^{1-\alpha}+q-\rho .
$$

In Appendix A, we show that the growth rate of $z$ is given by

$$
\frac{\dot{z}}{z}=A_{m} z^{\alpha-1} \chi^{1-\alpha}-\varpi(1-\chi)-q-\delta,
$$

where $\varpi=\frac{1-\alpha+\psi_{m}}{1-\alpha} B$, and the growth rate of $\chi$ is given by

$$
\frac{\dot{\chi}}{\chi}=\theta(1-\chi)-q+\delta_{\chi}
$$

where $\theta=\frac{\psi_{m}-\alpha}{\alpha} B$ and $\delta_{\chi}=\frac{B}{\alpha}-\delta$.

Given the reduce system, the dynamic equilibrium is a path $\{q, z, \chi\}$ such that, given the initial value of $z_{0}$ and $\chi_{0}$, solve equations (3.16), (3.17), and (3.18) and satisfies the transversality conditions.

\subsection{The equilibrium path}

We next characterize the equilibrium path. We define a balanced growth path (BGP, henceforth) as an equilibrium path along which the efficiency units of capital $z, q$, and $\chi$ remain constant, and, therefore, the aggregate physical capital, total expenditure consumption and human capital grow at a constant rate. The following propositions characterizes the BGP equilibrium. ${ }^{11}$

\footnotetext{
${ }^{10}$ We follow to Mulligan and Sala-i-Martin (1993) to reduce the dimension of the system to a threedimensional system to simplify the analysis.

${ }^{11}$ We provide all the proofs in the Appendix B.
} 
Proposition 3.1. There is a unique BGP along which the steady-state values of $q, z$, and $\chi$ are, respectively,

$$
\begin{aligned}
q^{*} & =\frac{B\left(1-\alpha+\psi_{m}\right)-\psi_{m}(\delta+\rho)}{\alpha}+\rho, \\
z^{*} & =\left(\frac{\delta+\rho}{B}\right)\left[\frac{\alpha(1-\alpha) A_{m}}{B\left(1-\alpha+\psi_{m}\right)-(\delta+\rho) \psi_{m}}\right]^{\frac{1}{1-\alpha}},
\end{aligned}
$$

and

$$
\chi^{*}=\frac{\delta+\rho}{B} .
$$

Proposition 3.2. Assume that $B>\rho+\delta$. The growth rate of aggregate physical capital $\left(\gamma_{k}\right)$, and total expenditure consumption $\left(\gamma_{c}\right)$ are constant along the BGP and are given by

$$
\gamma=\gamma_{k}=\gamma_{c}=\varphi \gamma_{h}=B-\delta-\rho,
$$

where $\gamma$ is the growth rate of GDP, $\gamma_{h}$ is the growth rate of human capital, and $\varphi$ is a factor of proportionality equal to $(1-\alpha) /\left(1-\alpha+\psi_{m}\right)$.

Proposition 3.3. If $\epsilon \neq 1$ and $\psi_{m} \neq \psi_{a}$ or $\psi_{m} \neq \psi_{s}$, then the sectoral composition of the economy changes along the $B G P$.

Proposition 3.4. Assume that $\psi_{m} \leq \alpha$. The BGP equilibrium is locally saddle-path stable.

Propositions (3.1) and (3.2) establish, on the one hand, that the steady state of the differential equations of the reduced system is unique and, in this equilibrium, aggregate physical capital, and the total consumption expenditure grow at the same constant rate. That implies that aggregate ratios, i.e., physical capital-output ratio are constant, which is consistent with the Kaldor's facts. Proposition (3.3) establishes, on the other hand, that changes in the sectoral composition occur along the balanced growth path if consumption goods are either complementary or substitutes. This result arises due to Edgeworth elasticity differs from one and, therefore, the marginal utility of each good depends on the relative prices, as follows from (2.6) and (2.7). To the extent the relatives prices changes, due to cross-sectoral differences in the strength of human capital externality, demand for goods and employment allocation across sectors change along the BGP. Proposition (3.4) establishes that, for a given imbalance between physical and human capital ratio that places the economy system outside of steady-state equilibrium, ${ }^{12}$ there exists a unique trajectory which converges to the BGP. ${ }^{13}$

Thus, Propositions (3.1), (3.2), (3.3) and (3.4) imply that the equilibrium path is consistent with the Kaldor-Kuznets facts and, consequently, show that the specifications of the model give rise to a generalized balanced growth path. Furthermore, these specifications have two implications for growth, structural change and development.

\footnotetext{
${ }^{12} \mathrm{An}$ imbalance is defined as a departure of the ratio of physical to human capital $\left(z_{0}\right)$ from the ratio that prevails in the long run $\left(z^{*}\right)$.

${ }^{13}$ In Appendix C, we show that both transversality conditions are always satisfied at the steady state under our assumptions.
} 
First, the model predicts that growth rates in economies with same fundamentals converge in the long run. However, differences in imbalances across countries imply differences in growth rates along the transition to the equilibrium path, as in the Lucas' model. For instance, a country with an abundance of physical capital focuses its investment on human capital, which increases the productivity and fosters the growth rate. As a consequence, these economies may exhibit permanent cross-country income differences during the transition and along the GBGP.

Second, given that the ratio of physical to human capital affects the employment shares, the model predicts that cross-country differences in imbalances imply differences in the sectoral composition of the economies. Furthermore, the model predicts differences in the pace of structural change across countries. The intuition of these results is as follows. An economy, with an abundance of physical capital that places it outside of the GBGP, would be characterized by an initial significant share of the non-educational sector in total employment. In this case, more labor is allocated to produce the relative-scarce factor: human capital. This shift of employment share in educational sector increases the growth rate of human capital, fosters the growth rates of sectoral TFP and, consequently, induce employment reallocation across economic activities. In this regard, the pace of structural change may vary across countries as long as it depends on the extent of imbalance in each economy.

\subsection{Structural change}

In order to analize the effect of imbalance on structure change along the transition and the GBGP, we follow to Ngai and Pissarides (2007). We first define structural change as the change in the allocation of employment shares. By taking-log-derivative of (3.7) and using (2.17), the growth rates of employment shares in agriculture and services sector are

$$
\begin{aligned}
& \frac{\dot{u}_{s}}{u_{s}}=(1-\epsilon) \frac{\dot{h}}{h}\left[\left(\psi_{m}-\psi_{s}\right)\left(1-\sigma_{s}\right)-\left(\psi_{m}-\psi_{a}\right) \sigma_{a}\right]+\frac{\dot{c} y}{c / y}+\frac{\dot{\chi}}{\chi}, \\
& \frac{\dot{u}_{a}}{u_{a}}=(1-\epsilon) \frac{\dot{h}}{h}\left[\left(\psi_{m}-\psi_{a}\right)\left(1-\sigma_{a}\right)-\left(\psi_{m}-\psi_{s}\right) \sigma_{s}\right]+\frac{c / y}{c / y}+\frac{\dot{\chi}}{\chi} .
\end{aligned}
$$

Note that structural change arises from two channels along the transition and the GBGP. The first channel, that corresponds to the first term in (3.22) and (3.23), shows the change in employment shares due to the bias of sectoral technical progress. In this case, changes in employment shares are induced by the changes in relative prices, which are captured by the variables $\sigma_{a}$ and $\sigma_{s}$. Given the assumption on the strength of sectoral externality, that is $\psi_{a}>\psi_{m}$ and $\psi_{m}>\psi_{s}$, and assuming $c \dot{\gamma} y=\dot{\chi}=0$ and $\dot{h}>0$, the first term in (3.22) is zero, and (3.23) is negative in the long run. That implies function employment share in agriculture will be decreasing, and labor is moving from this sector to manufacturing, services and educational sector. We call this effect as endogenous price effect.

The second channel, the second and the third terms in (3.22) and (3.23), shows the change in employment shares due to the imbalance of the ratio between physical and human capital. If the initial ratio between this two stocks of capital differs from 
its steady-state value, individuals decide either to allocate more labor into education sector or to allocate labor in the manufacturing sector to accumulate more physical capital. The intuition is as follows. Individuals decide to allocate more labor to education sector when human capital is relatively scarce to physical capital. In this case, the marginal return of human capital increases and more labor is allocated to educational sector instead of the sector which produces physical capital. Conversely, when physical capital is relatively scarce to human capital, individuals decide to allocate labor in the manufacturing sector. In this case, net marginal return on physical capital increases and more labor is allocated to the manufacturing sector. These differences in marginal returns of physical and human capital induce changes in labor and capital shares across sectors. We refer to this channel as the endogenous investment effect or imbalance effect on structural change. ${ }^{14}$

\section{Numerical analysis}

In this section, we analyze the effects of human capital accumulation on structural change and their implications for development. In particular, we propose two numerical exercises. First, we use this model to analyze the accuracy of this endogenous mechanism in explaining observed patterns of structural change in the United States along the 20th century, a period characterized by a rapid accumulation of human capital. That is, we analyze how consistent is the human capital accumulation to predict the levels of employment shares in agriculture, manufacturing, and services. Second, we extend the numerical analysis to focus on the role of human capital accumulation in explaining differences both in the sectoral composition of the economy and in the pace of structural change across countries.

To these ends, we propose the following strategy. In a first step, we calibrate the model to explain the structural change of the U.S. economy in the period 1947-2010. We focus on this period because of the fraction of the non-working time that individuals allocate to education is robustly constant, namely around a 0.11 , which is consistent with an economy on a BGP. ${ }^{15}$ In particular, we calibrate the model to match the time path of relative prices. We then obtain the simulated time path of employment shares based on the simulated relative prices. In a second step, we use our calibrated model to simulate transitional dynamics by varying the initial values of physical and human capital. We choose the initial values of these state variables such that the employment shares in non-educational sectors approach its actual value at the beginning of the 20th century. Then, we analyze the accuracy of our model to encompass the process of structural change and human capital accumulation along the century.

We use the model to ilustrate the role of human capital accumulation in explaining

\footnotetext{
${ }^{14}$ We highlight that both channels (price and imbalance effects) affect the structural change simultaneously and both channels reinforce each other. For instance, when human capital is relatively scarce, and differs from its steady-state value, the imbalance effect fosters reallocation of labor across sector, but also, it fosters the growth rate of human capital, and, therefore, the price effect on structural change.

${ }^{15}$ Ramey and Francis (2009) show that the fraction of available time devote to school has been increasing since the early 20 century. However, after the second world war, schooling time has been roughly constant.
} 
differences in the structural change along the development process between two countries. In particular, we investigate how differences in the initial ratio between physical and human capital can account for the difference both in the initial sectoral composition and in the pace of structural change across countries. To answer this question, we simulated the development process of two economies that are identical in all fundamentals, i.e., both countries start with the same level of GDP, but differ in the extent of initial imbalance. In what follows, we present the calibration strategy.

\subsection{Calibration}

To calibrate the model, we have assumed that the post-war U.S. economy is on the BGP since 1947. Then, we set $\alpha$ to match the average income labor share, which is about 0.65 according to the Economic President Report (2012). We set the values of $\rho$, $\delta, \psi_{m}$, and $B$ to match jointly the average of GDP growth rate, interest rate, physical capital-output ratio and the fraction of labor allocated in the educational sector for the period. ${ }^{16}$ We then set the values of $\eta_{a}$ and $\eta_{s}$ to match the employment shares in agriculture and services sectors in 1947. We normalized $A_{m}$, the technology level in manufacturing and set the values of $A_{s}$ and $A_{a}$ to match the relative price level of services and agricultural goods in 1947. Finally, we jointly set the values of the sector externalities $\psi_{s}$ and $\psi_{a}$, and elasticity of substitution $\epsilon$ to match the average growth rate of relative prices and minimize the root-mean-square error of the simulated employment shares for the period 1947-2010. Table 1 reports the values for all the parameters and targets.

$$
\text { [Insert Table 1] }
$$

\subsection{GBGP: U.S. economy (1947-2010)}

As mentioned before, we simulate the U.S. economy by assuming that it is on a BGP since 1947. Figures 1 and 2 plot the results of our numerical simulation. Figure 1 plots the time path of relative prices of agriculture and services. Not surprisingly, the model replicates the total variation in data: the rise of the relative price of services and the fall of the relative price of agriculture.

$$
\text { [Insert Figure 1] }
$$

We use the relative prices generated by the model to simulate the rest of variables in our economy. In particular, the shares in total employment of agriculture, manufacturing, and services for the period. Figure 2 shows the actual and simulated time paths of employment shares in the three broad sectors. A first visual exploration of our results shows that the model can replicate the main trends and explain the total variation in agriculture employment share but the model fails to explain the total variation in manufacturing and service employment shares for the calibrated values of the externalities. Although this result shows the limitations of the relative price

\footnotetext{
${ }^{16}$ Share in total employment of educational sector accounts for all workers that are related to the formation of human capital, that is, professors, trainers, scientists.
} 
mechanism to fully explain the structural change along the period; our results show that specifications of the model can fit the data well.

$$
\text { [Insert Figure 2] }
$$

\subsection{Transitional dynamics: U.S economy (1900-1947)}

In this section, we use our calibrated model to numerically analyze the effect of the imbalance in the ratio between physical and human capital on the pace of structural change in the U.S economy. With this purpose, we simulate transitional dynamics of the model by changing the initial value of the ratio of physical to human capital from its steady-state value. In particular, We chose their initial values of $k$ and $h$ such that the initial employment share non-educational sectors match their observed values in 1900 . Following this strategy, the initial value of the ratio between human and physical capital is below its steady-state value.

\section{[Insert Figure 3]}

Figure 3 shows the results of our numerical exercises. As can be seen with the naked eye, the model is capable of explaining both the rise and the fall of employment shares in services and agriculture sectors along all the 20th century. Furthermore, Figure 3 shows that the model's prediction does remarkably well in matching the hump-shaped in the manufacturing sector. These results arise in the model due to the Imbalance and Price mechanism are driving structural change along the transition path. The intuition of this results is as follows. Given the imbalance that places the economy outside of the BGP, the relatively scarce factor in the economy is human capital. This scarcity generates an incentive for individuals to allocate time to produce human capital. To this end, individuals reallocate labor from the non-educational to educational sector. As consequence, the stock of human capital increases. This increment in human capital stock yields sectoral productivity gains that promote the reallocation of employment from the agriculture (the sector with higher productivity growth) to manufacturing, services and educational sectors, which sequentially increases the human capital accumulation. These mechanisms affect each other fostering employment reallocation and, consequently, the pace of structural change.

$$
\text { [Insert Figure 4] }
$$

According to Buera and Kaboski (2009), traditional theories have lacked a robust quantitative explanation for the hump shape pattern of the manufacturing sector, with few exceptions, as in Foellmi and Zweimüller (2008); Buera and Kaboski (2012); and Comin, Lashkari, and Mestieri (2015). These papers show that a hump shape in manufacturing arises in a model that is characterized by non-homothetic preferences. Our findings show that a based-technology explanation could account for the humpshaped pattern of manufacturing employment based on the assumption of homothetic preferences and the imbalance effect introduced by human capital accumulation process.

Figure 4 plots the actual and simulated available time to schooling along the transitional path. In contrast with the results above, the fit of the simulated time path is 
low. This result is due to the growth rate of schooling, implied by the model, is higher than the actual growth rate at the early stage of economic development. Nonetheless the overestimation of the accumulation of human capital, the model replicates the secular trend in the accumulation of human capital in the United States. ${ }^{17}$ These results support the idea that human capital accumulation plays a key role in accounting for the structural change.

\subsection{Development patterns.}

In this section, we illustrate the role of imbalances in explaining the differences of structural change in two hypothetical countries along the development process. Literature of economic growth and development have stressed that sectoral composition and the pace of structural change vary significantly across countries. ${ }^{18}$ In light of our findings, we outline that a critical factor to explain cross-country differences is the imbalance between physical and human capital. Here, we propose to extend our framework to illustrate how initial relative human capital endowment affects the pace of structural change.

To this end, we simulated two economies, which we called countries A and B. These economies differ each other only in the initial endowments of physical and human capital, which implies they are identical in all fundamentals. In Country A, the initial stocks of physical and human capital are arbitrarily set equal to 0.85 and 0.378 , respectively. In Country B, the initial stocks are arbitrarily set equal to 0.93785 and 0.36 , respectively. We choose these values so that both countries exhibit the same GDP level at $t=0$. We then calculate the ratio of physical to human capital in both countries to determinate the distance from their steady-state values. Thus, Country A's ratio is 2.2487 , which is a $26 \%$ lower than its steady-state value. Country B's ratio is 2.605 , which is a $14 \%$ lower than its steady-state value. Note that human capital is relatively scarce in both countries. Given these initials values, Figure 5 plots the simulated time paths of GDP (levels and growth rates), and the structural change that arises in both economies. Two results emerge from this numerical exercise.

$$
\text { [Insert Figure 5] }
$$

First, we observe cross-country income differences increase along the transition path. This result arises due to the imbalance that places the economy A outside of the BGP is higher than the imbalance in Country B. The intuition is as follows. Given that human capital is more scarce in country A than Country B, the marginal return on investment in human capital is higher in Country A. The employment share in the educational sector increases more in Country A and, consequently, the stock of human capital and the growth rate of GDP increase. The cross-country differences in GDP growth are also plotted in Figure 5. Note that, as both economies accumulate human capital, imbalances converge to its steady-state values, and cross-country differences in GDP growth tend to vanish. As in Lucas (1988), our model also predicts that

\footnotetext{
${ }^{17}$ See Restuccia and Vandenbroucke (2013).

${ }^{18} \mathrm{Bah}$ (2011) shows that there are significant differences in the patterns of structural change across countries. In particular, he shows that, in average, Latin America, Africa, Asia shows differences with developed countries.
} 
countries will converge in growth rates in the long-run, but the income levels could be permanently different across countries.

Second, there is remarkable cross-country difference in the pace of structural change. Figure 5 plots the structural change in both countries along the transitional dynamics. Note that the employment share in agriculture is higher in Country A than in Country B at the beginning of the transition. In particular, the employment share in Country A is around $33 \%$, while this share is $27 \%$ in Country B. Notably, the sectoral composition of Country A converges on a similar sectoral profile than Country B in a short period. After 20 periods, the size of agriculture sector in both countries are almost equal. This result arises because the imbalance in Country A is higher than in Country B. In this case, the amount of employment allocated in the educational sector increase the growth rate of human capital. As mentioned before, this effect fosters the change in relative prices and, consequently, it promotes the structural change. Therefore, Country A shows a more remarkable structural change than Country B along the transition toward their respectively steady states. Furthermore, in the hypothetical case that initial condition put both countries on the BGP, both economies still show structural change due to the accumulation of human capital. In this case, both countries converge to the same sector composition, where the services sector is the dominant sector. These results show that human capital is a significant factor to explain not only observed structural along the development process in a country but also the crosscountry differences in the pace of structural change.

\section{Concluding remarks}

In this paper, we present a multi-sector growth model which allows for changes in sectoral composition and human capital accumulation along the balanced growth path. As occurs in multi-sector growth models based on the assumption of biased technical change, the structural change along the equilibrium path is driven by the changes in relative prices. A novelty in our proposal is that the growth of relative prices is endogenous and we show that the imbalance in the ratio between physical and human capital is a mechanism for structural change. By assuming that sectoral technical progress depends on the stock of human capital, the model is capable of replicating remarkable well the pace of structural change in the U.S economy during the twenty century.

We show that this result arises due to the imbalance between the two stocks of capital. In the model, if the initial ratio between this two stocks of capital differs from its long-run value, individuals decide either to allocate more employment in the education sector or to allocate employment in the manufacturing sector to accumulate more physical capital. When the relatively scarce factor in the economy is human capital, it generates incentives for individuals to allocate time to produce human capital and reallocate labor from the non-educational to educational sector. As consequence, the stock of human capital increases and yields sectoral productivity gains that promote the reallocation of employment from the agriculture to manufacturing, services, and educational sectors. This relocation of employment sequentially increases the human capital accumulation, which encourages employment reallocation and, consequently, the pace of structural change. 
We interpret this result as a suggestion to reconsider the role of human capital in explaining structural transformation in the spirit of the literature on development. According to this line of research, human capital accumulation is a significant factor behind the industrialization. It fosters sectoral technological progress through technology adoption or development of new technologies that accelerate the process of reallocation of labor across sectors (see Nelson and Phelps, 1966; Temple and Voth, 1998). In this regard, a natural extension of our paper is to investigate if, under this conditions both sectoral technological adoption, R\&D and human capital can explain the Kaldor-Kuznets facts. 


\section{References}

Acemoglu, Daron, and Veronica Guerrieri. "Capital Deepening and Nonbalanced Economic Growth." Journal of Political Economy 116, no. 3 (2008): 467-98.

Alonso-Carrera, and Raurich. "Labor Mobility, Structural Change and Economic Growth." Journal of Macroeconomics, 2018, Journal of Macroeconomics.

Alvarez-Cuadrado, Francisco, and Markus Poschke. "Structural Change Out of Agriculture: Labor Push versus Labor Pull." American Economic Journal: Macroeconomics 3, no. 3 (2011): 127-58.

Bah, El-Hadj M. "Structural Transformation Paths Across Countries." Emerging Markets Finance and Trade 47, no. 0 (2011): 5-19.

Benhabib, Jess, and Perli, Roberto. "Uniqueness and Indeterminacy: On the Dynamics of Endogenous Growth. (Symposium on Growth, Fluctuations and Sunspots: Confronting the Data)." Journal of Economic Theory 63, no. 1 (1994): 113.

Boppart, Timo. "Structural Change and the Kaldor Facts in a Growth Model With Relative Price Effects and Non-Gorman Preferences." Econometrica 82, no. 6 (2014): 2167-196.

Buera, Francisco J., and Joseph P. Kaboski. "Can Traditional Theories of Structural Change Fit the Data?" Journal of the European Economic Association 7, no. 2-3 (2009): 469-77.

Buera, Francisco J., and Joseph P. Kaboski. "Scale and the Origins of Structural Change." Journal of Economic Theory 147, no. 2 (2012): 684-712.

Comin, Diego; Lashkari,Danial; and Mestieri, Martí. "Structural Change with Long-run Income and Price Effects." NBER Working Paper Series, 2015. N/a.

Dennis, and İşcan. "Engel versus Baumol: Accounting for Structural Change Using Two Centuries of U.S. Data." Explorations in Economic History 46, no. 2 (2009): 186-202.

Duarte, Margarida, and Restuccia, Diego. "The Role of the Structural Transformation in Aggregate Productivity." The Quarterly Journal of Economics 125, no. 1 (2010): 12973.

Echevarría, Cristina. "Changes in Sectoral Composition Associated with Economic Growth." International Economic Review 38, no. 2 (1997): 431-52.

Foellmi, and Zweimüller. "Structural Change, Engel's Consumption Cycles and Kaldor's Facts of Economic Growth." Journal of Monetary Economics 55, no. 7 (2008): 1317328.

Valentinyi, Ákos, and Herrendorf, Berthold. "Measuring Factor Income Shares at the Sectoral Level." Review of economic dynamics 11, no. 4 (2008): 820-35. 
Herrendorf, Berthold, Christopher Herrington, and Ákos Valentinyi. "Sectoral Technology and Structural Transformation." American Economic Journal: Macroeconomics 7, no. 4 (2015): 104-33.

Herrendorf, Berthold; Rogerson, Richard; and Valentinyi, Ákos. "Growth and Structural Transformation," P. Aghion, Durlauf, Steven, Handbook of Economic Growth. Amsterdam and NewYork: North Holland, 2014, 855-941.

Historical Statistics of the United States - Millennial Edition, 2016.

Jones, C. "The Facts of Economic Growth." Handbook of Macroeconomics. Vol. 2. Elsevier B.V., 2016. 3-69.

Kongsamut, Piyabha, Sergio Rebelo, and Danyang Xie. "Beyond Balanced Growth." Review of Economic Studies 68, no. 4 (2001): 869-82.

Lucas, Jr., Robert E. "On the Mechanics of Economic Development." Journal of Monetary Economics 22 (1988): 3-42.

Meckl, Jürgen. "Structural Change and Generalized Balanced Growth." Journal of Economics 77, no. 3 (2002): 241-66.

Mulligan, Casey, and Xavier Sala-i-Martin. "Transitional Dynamics in Two-sector Models of Endogenous Growth." Quarterly Journal of Economics Cviii, no. 3 (1993): 739-73.

Nelson, Richard R., and Edmund S. Phelps. "Investment in Humans, Technological Diffusion, and Economic Growth." The American Economic Review 56, no. 1/2 (1966): 69-75.

Ngai, L. Rachel, and Christopher A Pissarides. "Structural Change in a Multisector Model of Growth." American Economic Review 97, no. 1 (2007): 429-43.

Ramey, Valerie A, and Neville Francis. "A Century of Work and Leisure." American Economic Journal: Macroeconomics 1, no. 2 (2009): 189-224.

Timmer, M. P., de Vries, G. J., \& de Vries, K. (2015). "Patterns of Structural Change in Developing Countries." . In J. Weiss, \& M. Tribe (Eds.), Routledge Handbook of Industry and Development. (pp. 65-83). Routledge.

Temple, and Voth. "Human Capital, Equipment Investment, and Industrialization." European Economic Review 42, no. 7 (1998): 1343-362.

United, States; President and Council of Economic, Advisers. "Economic Report of the President: Transmitted to the Congress February 2012, Together with the Annual Report of the Council of Economic Advisers," Washington[, D.C.]

Restuccia, Diego, and Guillaume Vandenbroucke. "A Century of Human Capital and Hours." Economic Inquiry 51, no. 3 (2013): 1849-866. 
Figures and Tables

Figure 1. Relative prices
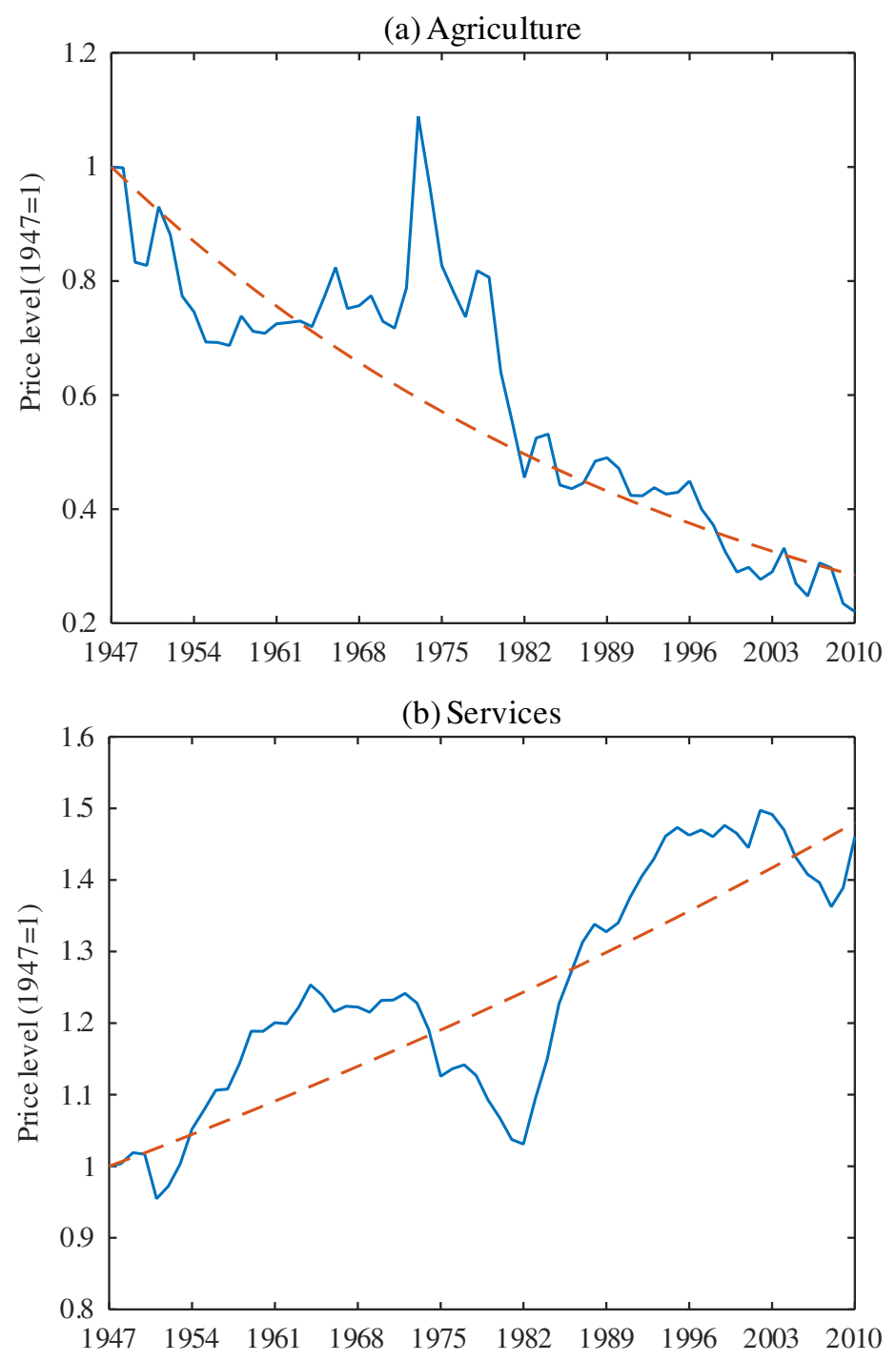
Figure 2. Structural Change, 1947-2010
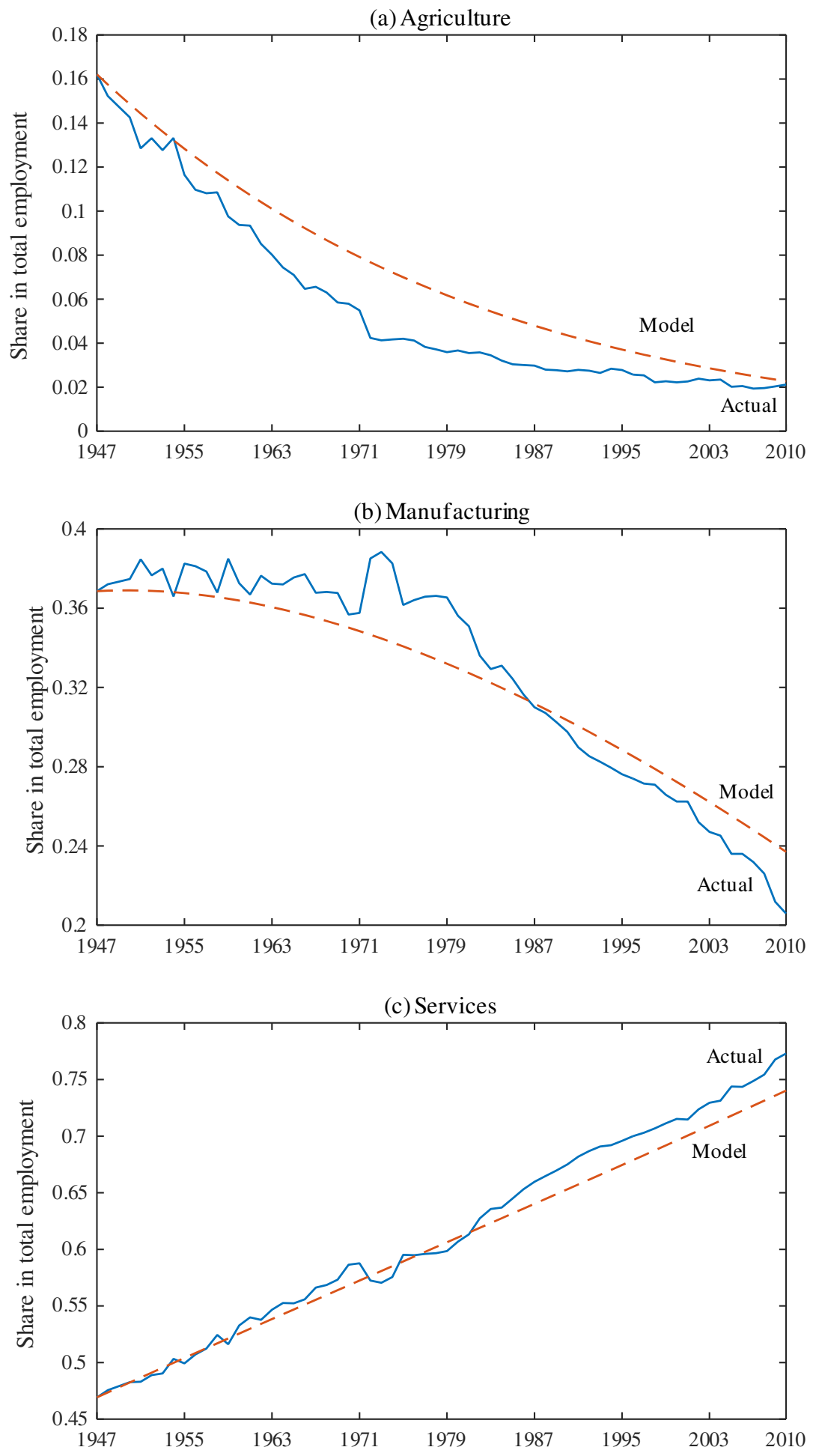
Figure 3. Structural Change, 1900-2010

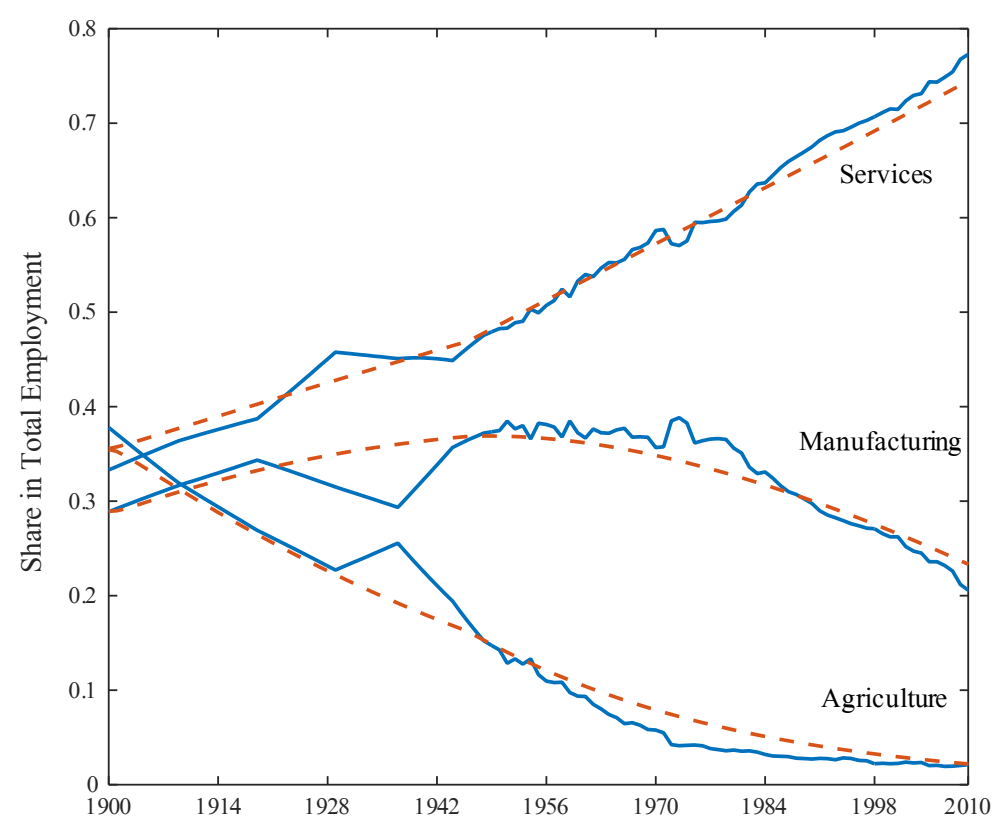

Figure 4.Time to schooling, 1900-2005

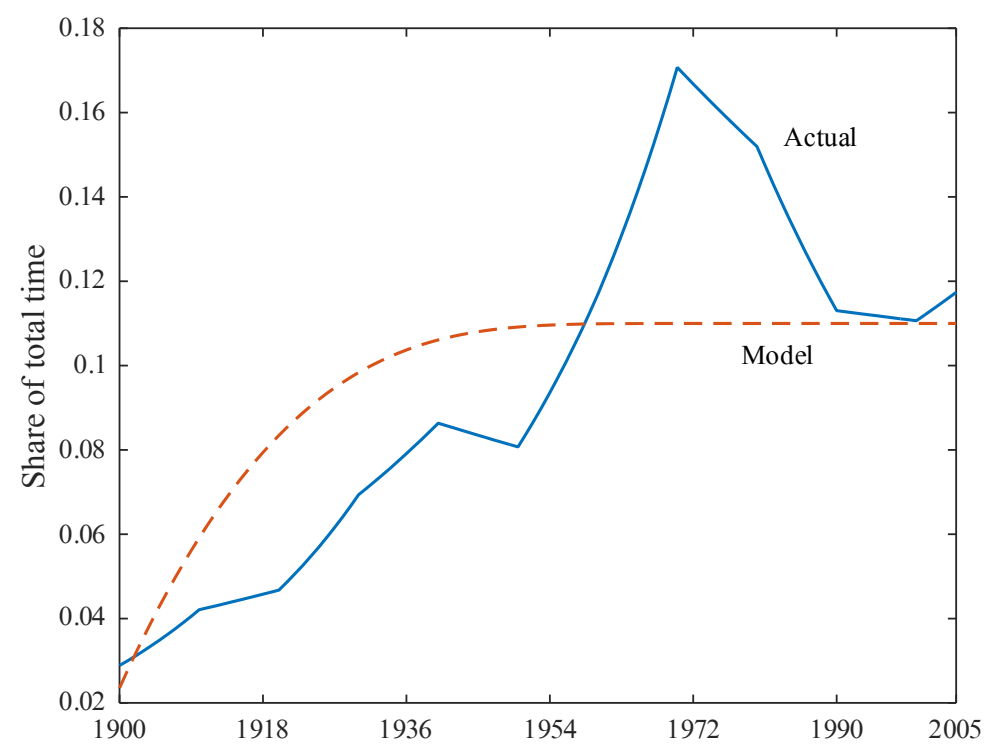


Figure 5. Two hypothetical countries
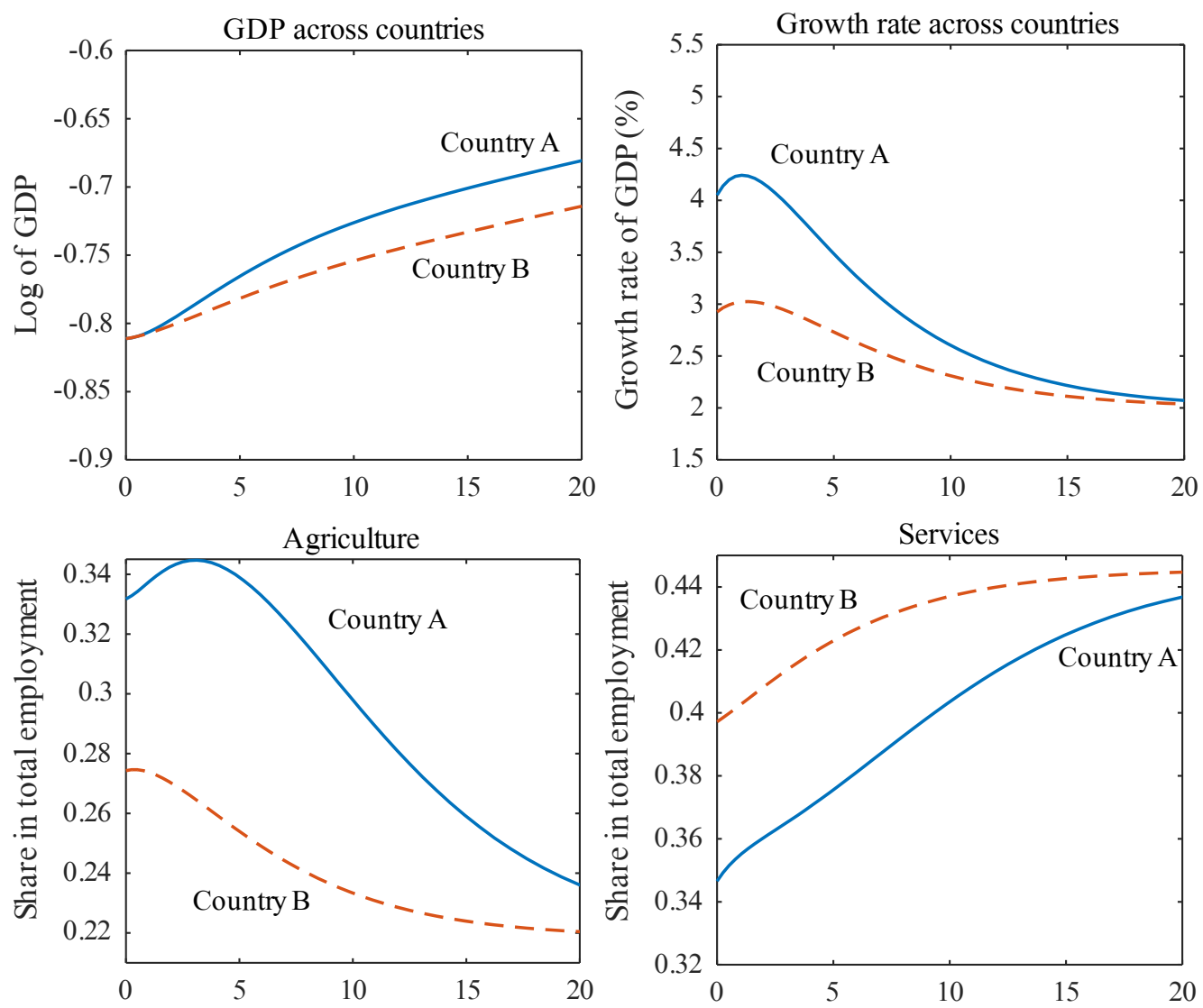
Table 1: Calibration

\begin{tabular}{|c|c|c|c|c|}
\hline Parameters & Values & Targets & Data & Model \\
\hline$\alpha$ & 0.377 & Labor income share & 0.650 & 0.650 \\
\hline$\rho$ & 0.028 & Interest rate & 0.052 & 0.052 \\
\hline$\delta$ & 0.090 & Capital-output ratio & 2.64 & 2.64 \\
\hline$\psi_{m}$ & 0.368 & GDP growth rate & 0.023 & 0.023 \\
\hline$B$ & 0.133 & Employment share in educational sector & 0.110 & 0.110 \\
\hline $\bar{\eta}_{a}$ & 0.379 & Employment share in agriculture (1947) & 0.162 & 0.162 \\
\hline $\bar{\eta}_{s}$ & 6.140 & Employment share in services (1947) & 0.469 & 0.469 \\
\hline$A_{a}$ & 0.468 & Relative price of agriculture (1947) & 3.706 & 3.706 \\
\hline$A_{s}$ & 1.213 & Relative price of services (1947) & 0.698 & 0.698 \\
\hline$A_{m}$ & 1.000 & Normalized & - & - \\
\hline$\psi_{a}$ & 1.166 & Growth rare of R. price (agriculture) & -0.02 & -0.015 \\
\hline$\psi_{s}$ & 0.005 & Growth rare of R. price (services) & 0.005 & 0.005 \\
\hline$\epsilon$ & $1 e-05$ & Minimize RMSE & - & - \\
\hline$z_{0}$ & 0.996 & Employment share in manufacturing (1900) & 0.294 & 0.294 \\
\hline
\end{tabular}

We report data of average labor income share from Penn World Table version 9.0. Average GDP growth rate from BEA, series GDPC1 for the period 1948-2010. We obtained the employment shares and relative prices from Timmer, de Vries, and de Vries. (2015). Average interest rate comes from Alonso-Carrera and Raurich (2018), the physical capital-output ratio is reported by Jones (2016), and we take the fraction of labor allocated in the educational sector in 1947 from Historical Statistics of the United States, Millennia edition (2016). 


\section{Appendix}

\section{A. Derivation of the main equations}

\section{Solution to the representative consumer optimization problem.}

The representative agent maximizes the discounted sum of utilities

$$
\int_{0}^{\infty} e^{-\rho t} U(\tilde{c}) d t
$$

subject to (2.3), (2.4) and (2.5), where $\rho>0$ is the subjective discount rate.

The current-value Hamiltonian function associated with the maximization problem is

$$
\mathcal{H}=\ln \tilde{c}+\mu_{1}\left(w h+r k-c_{m}-p_{s} c_{s}-p_{a} c_{a}-I_{k}-p_{h} I_{h}\right)+\mu_{2}\left(I_{k}-\delta k\right)+\mu_{h} I_{h}
$$

where $\mu_{1}, \mu_{2}$ and $\mu_{h}$ are the co-state variables corresponding to the constraints (2.3), (2.4) and (2.5), respectively. The first order conditions are

$$
\begin{aligned}
\eta_{a} \tilde{c}^{\frac{1-\epsilon}{\epsilon}} c_{a}^{-\frac{1}{\epsilon}} & =p_{a} \mu_{1}, \\
\eta_{s} \tilde{c}^{\frac{1-\epsilon}{\epsilon}} c_{s}^{-\frac{1}{\epsilon}} & =p_{s} \mu_{1}, \\
\eta_{m} \tilde{c}^{\frac{1-\epsilon}{\epsilon}} c_{m}^{-\frac{1}{\epsilon}} & =\mu_{1}, \\
\mu_{1} & =\mu_{2}, \\
p_{h} \mu_{1} & =\mu_{h}, \\
r \mu_{1}-\delta \mu_{2} & =-\dot{\mu}_{2}+\rho \mu_{2}, \\
w \mu_{1} & =-\dot{\mu}_{h}+\rho \mu_{h} .
\end{aligned}
$$

\section{Euler's equation.}

To obtain the Euler equation in the main text, we first combine (A.1), (A.3), (A.2) and (A.3) to obtain

$$
\begin{aligned}
c_{a} & =\left(\frac{\eta_{a}}{\eta_{m}}\right)^{\epsilon} \frac{c_{m}}{p_{a}^{\epsilon}}, \\
c_{s} & =\left(\frac{\eta_{s}}{\eta_{m}}\right)^{\epsilon} \frac{c_{m}}{p_{s}^{\epsilon}} .
\end{aligned}
$$

By substituting $c_{a}$ and $c_{s}$ in (2.2) we obtain that

$$
\tilde{c}=\left[p_{a}^{1-\epsilon}\left(\frac{\eta_{a}}{\eta_{m}}\right)^{\epsilon}+1+p_{s}^{1-\epsilon}\left(\frac{\eta_{s}}{\eta_{m}}\right)^{\epsilon}\right]^{\frac{\epsilon}{\epsilon-1}} \eta_{m}^{\frac{\epsilon}{\epsilon-1}} c_{m},
$$

and substituting (A.9) in (A.3), we obtain

$$
\frac{1}{c_{m}}=\mu_{1}\left[1+p_{a}^{1-\epsilon}\left(\frac{\eta_{a}}{\eta_{m}}\right)^{\epsilon}+p_{s}^{1-\epsilon}\left(\frac{\eta_{s}}{\eta_{m}}\right)^{\epsilon}\right] .
$$


Taking log-derivatives in (A.10), we obtain that the growth rate of manufacturing consumption is

$$
\frac{\dot{c}_{m}}{c_{m}}=-\frac{\dot{\mu}_{1}}{\mu_{1}}-(1-\epsilon)\left(\sigma_{a} \frac{\dot{p}_{a}}{p_{a}}+\sigma_{s} \frac{\dot{p}_{s}}{p_{s}}\right),
$$

where $\bar{\eta}_{a}=\left(\frac{\eta_{a}}{\eta_{m}}\right)^{\epsilon}, \bar{\eta}_{s}=\left(\frac{\eta_{s}}{\eta_{m}}\right)^{\epsilon}$, and

$$
\begin{aligned}
\sigma_{a} & =\frac{\bar{\eta}_{a} p_{a}^{1-\epsilon}}{1+\bar{\eta}_{a} p_{a}^{1-\epsilon}+\bar{\eta}_{s} p_{s}^{1-\epsilon}}, \\
\sigma_{s} & =\frac{\bar{\eta}_{s} p_{s}^{1-\epsilon}}{1+\bar{\eta}_{a} p_{a}^{1-\epsilon}+\bar{\eta}_{s} p_{s}^{1-\epsilon}} .
\end{aligned}
$$

Finally, we substitute (A.4) in (A.6) to obtain

$$
r-\rho-\delta=-\frac{\dot{\mu}_{2}}{\mu_{2}},
$$

and from (A.4) implies that

$$
-\frac{\dot{\mu}_{1}}{\mu_{1}}=-\frac{\dot{\mu}_{2}}{\mu_{2}}=r-\rho-\delta .
$$

By substituting (A.12) in (A.10), we obtain

$$
\frac{\dot{c}_{m}}{c_{m}}=r-\rho-\delta-(1-\epsilon)\left(\sigma_{a} \frac{\dot{p}_{a}}{p_{a}}+\sigma_{s} \frac{\dot{p}_{s}}{p_{s}}\right)
$$

which is the equation (2.8) in the main text.

\section{The sectoral allocation of capital and relative prices}

Competitive firms in the production sector, namely agriculture, manufacturing and services, maximize profits by choosing labor and capital. The maximization problem is

$$
\max \pi_{i}=p_{i} y_{i}-r\left(s_{i} k\right)-w\left(u_{i} h\right)
$$

where

$$
y_{i}=A_{i}\left(s_{i} k\right)^{\alpha}\left(u_{i} h\right)^{1-\alpha} \bar{h}^{\psi_{i}} .
$$

Then the first order conditions are

$$
\begin{aligned}
p_{a}(1-\alpha) \frac{A_{a}\left(s_{a} k\right)^{\alpha}\left(u_{a} h\right)^{1-\alpha} \bar{h}^{\psi_{a}}}{u_{a} h} & =w, \\
p_{a} \alpha \frac{A_{a}\left(s_{a} k\right)^{\alpha}\left(u_{a} h\right)^{1-\alpha} \bar{h}^{\psi_{a}}}{s_{a} k} & =r, \\
p_{s}(1-\alpha) \frac{A_{s}\left(s_{s} k\right)^{\alpha}\left(u_{s} h\right)^{1-\alpha} \bar{h}^{\psi_{s}}}{u_{s} h} & =w, \\
p_{s} \alpha \frac{A_{s}\left(s_{s} k\right)^{\alpha}\left(u_{s} h\right)^{1-\alpha} \bar{h}^{\psi_{s}}}{s_{s} k} & =r,
\end{aligned}
$$




$$
\begin{aligned}
(1-\alpha) \frac{A_{m}\left(s_{m} k\right)^{\alpha}\left(u_{m} h\right)^{1-\alpha} \bar{h}^{\psi_{m}}}{u_{m} h} & =w, \\
\alpha \frac{A_{m}\left(s_{m} k\right)^{\alpha}\left(u_{m} h\right)^{1-\alpha} \bar{h}^{\psi_{m}}}{s_{m} k} & =r,
\end{aligned}
$$

where $p_{a}$ and $p_{s}$ are the relative prices of agriculture and services sectors. Finally, firms in the educational sector, choose labor until

$$
p_{h} B=w
$$

where $p_{h}$ is the relative price of human capital in units of manufacturing good. From combining (A.14), (A.16) and (A.18), we obtain

$$
\begin{aligned}
& p_{a}=\frac{A_{m}}{A_{a}}\left(\frac{s_{m} u_{a}}{s_{a} u_{m}}\right)^{\alpha} \bar{h}^{\psi_{m}-\psi_{a}}, \\
& p_{s}=\frac{A_{m}}{A_{s}}\left(\frac{s_{m} u_{s}}{s_{s} u_{m}}\right)^{\alpha} \bar{h}^{\psi_{m}-\psi_{s}},
\end{aligned}
$$

and from equations (A.15), (A.17) and (A.19) we obtain that

$$
\begin{aligned}
& p_{a}=\frac{A_{m}}{A_{a}} \frac{\left(s_{a} u_{m}\right)^{1-\alpha}}{\left(s_{m} u_{a}\right)^{1-\alpha}} \bar{h}^{\psi_{m}-\psi_{a}}, \\
& p_{s}=\frac{A_{m}}{A_{s}} \frac{\left(s_{s} u_{m}\right)^{1-\alpha}}{\left(s_{m} u_{s}\right)^{1-\alpha}} \bar{h}^{\psi_{m}-\psi_{s}} .
\end{aligned}
$$

From (A.21), (A.22), (A.23), and (A.24) we obtain that labor and capital shares must satisfy that

$$
\begin{aligned}
& s_{a} u_{m}=s_{m} u_{a}, \\
& s_{s} u_{m}=s_{m} u_{s} .
\end{aligned}
$$

From the market clearing condition, $\sum_{i=a, s, m} s_{i}=1$, we obtain that capital shares are given by

$$
\begin{aligned}
s_{s} & =\frac{u_{s}}{u_{m}+u_{s}+u_{a}}, \\
s_{a} & =\frac{u_{a}}{u_{m}+u_{s}+u_{a}}, \\
s_{m} & =\frac{u_{m}}{u_{m}+u_{s}+u_{a}} .
\end{aligned}
$$

which is the equation (2.14) in the main text. The relative prices of services and agriculture good is obtained by substituting (A.27) in (A.23) and (A.24) and taking into account $s_{a}+s_{m}+s_{s}=1$. Thus, relative prices are

$$
p_{a}=\frac{A_{m}}{A_{a}} \bar{h}^{\psi_{m}-\psi_{a}}
$$

and

$$
p_{s}=\frac{A_{m}}{A_{s}} \bar{h}^{\psi_{m}-\psi_{s}}
$$


which is the equation (2.15) in the main text. We obtain the relative price of human capital by susbtituting equation (A.14) in (A.20), and taking into account the capital shares in (A.27) to obtain the relative price of human capital

$$
p_{h}=(1-\alpha) \frac{A_{m}}{B}\left(\frac{1}{u_{m}+u_{s}+u_{a}} \frac{k}{h}\right)^{\alpha} \bar{h}^{\psi_{m}} .
$$

\section{Aggregate economy}

To characterize the aggregate economy, we first obtain aggregate output and the total consumption expenditure in our economy. Let $Q$ stands for the gross output of our economy (henceforth, GDP). Then, GDP is

$$
Q=y+p_{h} y_{h}
$$

where $y=y_{m}+p_{s} y_{s}+p_{a} y_{a}$ is the sum of the value of output in the non-educational sectors. Given the relative prices (2.15) and sectoral production function (2.10), together the efficient capital allocation (A.27), and the fact that all workers in the economy are identical, $\bar{h}=h$, we obtain the value of output in the non-educational sectors is

$$
y=A_{m} k^{\alpha}\left(u_{m}+u_{a}+u_{s}\right)^{1-\alpha} h^{1-\alpha+\psi_{m}} .
$$

Total consumption expenditure is defined as follows

$$
c=c_{m}\left(1+\bar{\eta}_{a} p_{a}^{1-\epsilon}+\bar{\eta}_{s} p_{s}^{1-\epsilon}\right) .
$$

\section{The sectoral allocation of labor}

We use the ratio between (A.29) and (A.30) to characterize the employment shares in this economy. This ratio is equal to

$$
\frac{c}{y}=\frac{c_{m}\left(1+\bar{\eta}_{a} p_{a}^{1-\epsilon}+\bar{\eta}_{s} p_{s}^{1-\epsilon}\right)}{A_{m} k^{\alpha}\left(u_{m}+u_{s}+u_{a}\right)^{1-\alpha} h^{1-\alpha+\psi_{m}}},
$$

we take into account that the constraints $p_{a} c_{a}=p_{a} y_{a}$ and $p_{s} c_{s}=p_{s} y_{s}$. Using (A.8) relative prices (2.15), sectoral production function in (2.10), together with the efficient capital allocation (A.27), we obtain

$$
\begin{aligned}
\frac{\bar{\eta}_{a} p_{a}^{1-\epsilon} c_{m}}{A_{m} k^{\alpha} h^{1-\alpha+\psi_{m}}\left(u_{m}+u_{s}+u_{a}\right)^{1-\alpha}} & =\frac{u_{a}}{u_{m}+u_{s}+u_{a}} . \\
\frac{\bar{\eta}_{s} p_{s}^{1-\epsilon} c_{m}}{A_{m} k^{\alpha} h^{1-\alpha+\psi_{m}}\left(u_{m}+u_{s}+u_{a}\right)^{1-\alpha}} & =\frac{u_{s}}{u_{m}+u_{s}+u_{a}} .
\end{aligned}
$$

Now, we use (A.31) to solve for $c_{m}$ as follows

$$
c_{m}=\frac{A_{m} k^{\alpha}\left(u_{m}+u_{s}+u_{a}\right)^{1-\alpha} h^{1-\alpha+\psi_{m}}}{\left(1+\bar{\eta}_{a} p_{a}^{1-\epsilon}+\bar{\eta}_{s} p_{s}^{1-\epsilon}\right)} \frac{c}{y},
$$


and substituting in (A.32) and (A.33), we obtain

$$
\begin{aligned}
& \frac{u_{a}}{u_{m}+u_{s}+u_{a}}=\sigma_{a} \frac{c}{y}, \\
& \frac{u_{s}}{u_{m}+u_{s}+u_{a}}=\sigma_{s} \frac{c}{y} .
\end{aligned}
$$

By substituting (A.34) and (A.35) in (A.27), we find the physical capital share in agriculture as a function of relative prices,

$$
s_{a}=\sigma_{a} \frac{c}{y}, \text { and } s_{s}=\sigma_{s} \frac{c}{y},
$$

which are equations (3.6) in the main text. To find the share of physical capital in manufacturing sector, equation (3.5) in the main text, we substitute the share in agriculture and service in the constraint $s_{m}=1-s_{a}-s_{s}$. Thus,

$$
s_{m}=1-\sigma \frac{c}{y},
$$

where $\sigma=\sigma_{a}+\sigma_{s}$. Finally, we find the employment shares in agriculture, manufacturing and services. We use equation (A.28) to find manufacturing employment share as a function of the employment share in agriculture and services as follows. First, we obtain the following expression from (A.28):

$$
\left(u_{a}+u_{m}+u_{s}\right)^{\alpha}=(1-\alpha) \frac{A_{m}}{B} \frac{1}{p_{h}}(k)^{\alpha-1} h^{1-\alpha+\psi_{m}}\left(\frac{k}{h}\right),
$$

Second, we substitute the stationary variable $z$, defined in (3.13), in (A.36) to obtain the following expression

$$
\left(u_{a}+u_{m}+u_{s}\right)=(1-\alpha) \frac{A_{m}}{B} \frac{z^{\alpha-1}}{p_{h}}\left(\frac{k}{h}\right) \equiv \chi .
$$

Substituting (2.15) and (A.27) in (A.15), we obtain that

$$
r=\alpha A_{m}\left(\frac{k}{u_{m}+u_{s}+u_{a}}\right)^{\alpha-1} h^{1-\alpha+\psi_{m}}
$$

and using (3.13), we obtain

$$
r=\alpha A_{m} z^{\alpha-1} \chi^{1-\alpha},
$$

and from (A.20), we obtain that

$$
w=p_{h} B .
$$




\section{Differential equations}

Total consumption expenditure is obtained by substituting (2.15) and (A.8) in $c=c_{m}+p_{a} c_{a}+p_{s} c_{s}$. Thus, we obtain

$$
c=c_{m}\left(1+\bar{\eta}_{a} p_{a}^{1-\epsilon}+\bar{\eta}_{s} p_{s}^{1-\epsilon}\right),
$$

which is equation (3.4) in the main text. Using (A.11), we can write total consumption expenditure as follows

$$
c=\frac{c_{m}}{\frac{1}{\left(1+\bar{\eta}_{a} p_{a}^{1-\epsilon}+\bar{\eta}_{s} p_{s}^{1-\epsilon}\right)}}=\frac{c_{m}}{1-\left(\sigma_{a}+\sigma_{s}\right)},
$$

and, using $\sigma_{a}+\sigma_{s}=\sigma$, we obtain

$$
c=\frac{c_{m}}{1-\sigma} .
$$

By taking log-derivatives in (A.30), we obtain

$$
\frac{\dot{c}}{c}=\frac{\dot{c}_{m}}{c_{m}}+\frac{1}{\left(1+\bar{\eta}_{a} p_{a}^{1-\epsilon}+\bar{\eta}_{s} p_{s}^{1-\epsilon}\right)}\left[(1-\epsilon) \bar{\eta}_{a} p_{a}^{1-\epsilon} \frac{\dot{p}_{a}}{p_{a}}+(1-\epsilon) \bar{\eta}_{s} p_{s}^{1-\epsilon}\right]
$$

and using (A.13) and definitions in (A.11), we obtain

$$
\begin{aligned}
& \frac{\dot{c}}{c}=r-\rho-\delta-(1-\epsilon)\left(\sigma_{a} \frac{\dot{p}_{a}}{p_{a}}+\sigma_{s} \frac{\dot{p}_{s}}{p_{s}}\right)+(1-\epsilon)\left(\sigma_{a} \frac{\dot{p}_{a}}{p_{a}}+\sigma_{s} \frac{\dot{p}_{s}}{p_{s}}\right) \\
& \frac{\dot{c}}{c}=r-\delta-\rho . \\
& \frac{\dot{c}}{c}=\alpha A_{m} z^{\alpha-1} \chi^{1-\alpha}-\delta-\rho .
\end{aligned}
$$

The growth rate of physical capital is obtained as follows. From definition of $\mathrm{z}$, we obtain that $k^{\alpha-1}=\frac{z^{\alpha-1}\left(u_{m}+u_{s}+u_{a}\right)^{\alpha-1}}{h^{1-\alpha+\psi_{m}}}$. By substituting this results in $\dot{k} / k$, we obtain

$$
\frac{\dot{k}}{k}=A_{m} z^{\alpha-1} \chi^{1-\alpha} \frac{u_{m}}{\left(u_{m}+u_{s}+u_{a}\right)}-\frac{c_{m}}{k}-\delta .
$$

By substituting $u_{m}=\chi\left(1-\sigma \frac{c}{y}\right),\left(u_{a}+u_{m}+u_{s}\right)=\chi$, and $c(1-\sigma)=c_{m}$, and $y / k=A_{m} z^{\alpha-1}$ equation above can be rewritten as

$$
\begin{aligned}
\frac{\dot{k}}{k} & =A_{m} z^{\alpha-1} \chi^{1-\alpha}\left(1-\sigma \frac{c}{y}\right)-(1-\sigma) \frac{c}{y} \frac{y}{k}-\delta \\
& =A_{m} z^{\alpha-1} \chi^{1-\alpha}-[\sigma+(1-\sigma)] \frac{c}{y} A_{m} z^{\alpha-1} \chi^{1-\alpha}-\delta \\
& =A_{m} z^{\alpha-1} \chi^{1-\alpha}-\frac{c}{k}-\delta
\end{aligned}
$$


and using $q=c / k$, we obtain equation in (3.14).

The growth rate of relative price of human capital is obtained as follows. We combine (A.4), (A.5), (A.6), and (A.7) to obtain:

$$
\frac{\dot{p}_{h}}{p_{h}}=r-\delta-\frac{w}{p_{h}},
$$

and using (A.38) and (A.39), we obtain that

$$
\frac{\dot{p}_{h}}{p_{h}}=\alpha A_{m} z^{\alpha-1} \chi^{1-\alpha}-\delta-B .
$$

Then, we obtain the growth rate of $z$ by taking log-derivatives in (3.13) and (A.37), we obtain that

$$
\frac{\dot{z}}{z}=\frac{1}{\alpha}\left(\frac{\dot{p}_{h}}{p_{h}}-\frac{\psi_{m}}{1-\alpha} \frac{\dot{h}}{h}\right),
$$

and using (3.12) and (A.40), we can rewrite $\dot{z} / z$ as follows

$$
\frac{\dot{z}}{z}=A_{m} z^{\alpha-1} \chi^{1-\alpha}-\varpi(1-\chi)-q-\delta,
$$

where where $\varpi=\frac{1-\alpha+\psi_{m}}{1-\alpha} B$. Finally, we obtain the growth rate of $\chi$ by taking logderivatives in (A.37), to obtain

$$
\frac{\dot{\chi}}{\chi}=(\alpha-1) \frac{\dot{z}}{z}-\frac{\dot{p}_{h}}{p_{h}}+\frac{\dot{k}}{k}-\frac{\dot{h}}{h},
$$

and substituting (3.14), (3.12), (3.17) and (A.40), and after some algebra, we obtain

$$
\frac{\dot{\chi}}{\chi}=\theta(1-\chi)-q+\delta_{\chi}
$$

where $\theta=\left(\frac{\psi_{m}-\alpha}{\alpha}\right) B$ and $\delta_{\chi}=\frac{B}{\alpha}-\delta$. 


\section{B. Proof of Propositions}

Proof of Proposition 3.1. At steady state, the growth rates of transformed variables $z, q$ and $\chi$ are equal to zero by definition, then we obtain the following system of equations,

$$
\begin{aligned}
& 0=A_{m} z^{\alpha-1} \chi^{1-\alpha}-\varpi(1-\chi)-q-\delta \\
& 0=(\alpha-1) A_{m} z^{\alpha-1} \chi^{1-\alpha}+q-\rho \\
& 0=\theta(1-\chi)-q+\delta_{\chi}
\end{aligned}
$$

It is straightforward to show that there exists a unique values for $z, q$ and $\chi$ that solve the system. From (B.3) here exist a unique value for $\chi$ such that satisfied other equations.

$$
\chi^{*}=\frac{(\delta+\rho)}{B},
$$

substituting this value into (B.1) and (B.2), we obtain

$$
\begin{gathered}
z^{*}=\left(\frac{\alpha(1-\alpha) A_{m}}{B\left(1-\alpha+\psi_{m}\right)-(\delta+\rho) \psi_{m}}\right)^{\frac{1}{1-\alpha}}\left(\frac{\delta+\rho}{B}\right), \\
q^{*}=\frac{B\left(1-\alpha+\psi_{m}\right)}{\alpha}+\rho-\frac{(\delta+\rho) \psi_{m}}{\alpha}
\end{gathered}
$$

Proof of Proposition-3.2. By substituting $z^{*}, q^{*}$ and $\chi^{*}$ in $\frac{\dot{k}}{k}$ and $\frac{\dot{c}}{c}$, we obtain

$$
\frac{\dot{k}}{k}=\frac{\dot{c}}{c}=\frac{[B-(\delta+\rho)]\left(1-\alpha+\psi_{3}\right)}{1-\alpha}
$$

and given $\chi^{*}$, the growth rate of human capital is

$$
\frac{\dot{h}}{h}=B-\rho-\delta
$$

where we can define the parameter $\phi=\frac{1-\alpha}{1-\alpha+\psi_{m}}$ and substitute it in $k$ and $c$ taking into account $\frac{\dot{h}}{h}$.

Proof of Proposition-3.4. Let $\mathrm{J}$ be the Jacobian matrix of the system of differential equations formed by (3.16) (3.17) and (3.18)

$$
J=\left(\begin{array}{lll}
\frac{\partial \dot{q}}{\partial q} & \frac{\partial \dot{q}}{\partial z} & \frac{\partial \dot{q}}{\partial \chi} \\
\frac{\partial z}{\partial q} & \frac{\partial z}{\partial z} & \frac{\partial z}{\partial \chi} \\
\frac{\partial \chi}{\partial q} & \frac{\partial \chi}{\partial z} & \frac{\partial \chi}{\partial \chi}
\end{array}\right)
$$

and evaluating the Jacobian matrix at the steady state, we obtain

$$
J^{*}=\left(\begin{array}{ccc}
\Psi+\rho & (1-\alpha) \Psi \frac{q^{*}}{z^{*}} & \frac{(1-\alpha)}{\alpha} \Psi \frac{q^{*}}{\chi^{*}} \\
-z^{*} & -\Psi & \frac{\Psi}{1-\alpha} \frac{z^{*}}{\chi^{*}}+\varpi z^{*} \\
-\chi^{*} & 0 & \frac{B}{\alpha}\left(\alpha-\psi_{m}\right) \chi^{*}
\end{array}\right),
$$


where

$$
\Psi=\frac{B(1-\alpha)+(B-\delta-\rho) \psi_{m}}{\alpha} .
$$

The Trace of the Jacobian matrix is

$$
\operatorname{Tr}(J)=\rho+\frac{\left(\alpha-\psi_{m}\right)(\delta+\rho)}{\alpha},
$$

and the sign of the Trace will be determinant by

$$
\operatorname{Tr}(J)=\left\{\begin{array}{lll}
<0, & \text { if } & \psi_{m} \in\left(\alpha \frac{\delta+2 \rho}{\delta+\rho}, \infty\right), \\
>0, & \text { if } & \psi_{m} \in\left(-\infty, \alpha \frac{\delta+2 \rho}{\delta+\rho}\right) .
\end{array} .\right.
$$

The Determinate of the Jacobian matrix at the steady state is

$$
\operatorname{det}(J)=-\Psi\left[B \chi^{*}+\frac{\Psi}{\alpha}\right] q^{*} .
$$

In a $3 \times 3$ system, if $\operatorname{Tr}(J)>0$ and $\operatorname{det}(J)<0$ imply that there are one negative latent root and two positive latent roots of $\mathrm{J}$ matrix and, in this case, the steady state equilibrium is a saddle point and the equilibrium transitional path is locally unique. The assumption of $B>\delta+\rho$, for a positive growth rate of GDP, implies that $q^{*}>0$ and, given that $\chi^{*} \in(0,1)$, the sign of the determinate is negative. Therefore, the steady state equilibrium is a saddle point and the equilibrium transitional path is locally unique if $\psi_{m} \in\left(0, \alpha \frac{\delta+2 \rho}{\delta+\rho}\right)$. That is

$$
\operatorname{Tr}(J)>0 \text { and } \operatorname{det}(J)<0 \text {, if } \psi_{m} \in\left(0, \alpha \frac{\delta+2 \rho}{\delta+\rho}\right)
$$

\section{Transversality conditions}

Following Benhabib and Perli (1994), we show that both transversality conditions are satisfied at the steady state. For the first condition, $\lim _{t \rightarrow \infty}\left(e^{-\rho t} \mu_{2} k\right)=0$, to be satisfied it must be that

$$
\lim _{t \rightarrow \infty}\left(-\rho+\frac{\dot{\mu}_{2}}{\mu_{2}}+\frac{\dot{k}}{k}\right)<0
$$

Substituting equations (3.14) and (A.12) for $\dot{k} / k$ and $\dot{\mu}_{2} / \mu_{2}$, we obtain

$$
-\left[(\alpha-1) A_{m} z^{* \alpha-1} \chi^{* 1-\alpha}+q^{*}\right]<0
$$

and, substituting $z^{*}$ and $\chi^{*}$, we obtain

$$
-\left[\frac{(\delta+\rho) \psi_{m}-B\left(1-\alpha+\psi_{m}\right)}{\alpha}+\frac{B\left(1-\alpha+\psi_{m}\right)-\psi_{m}(\delta+\rho)}{\alpha}+\rho\right]<0,
$$


which is always equal to $-\rho$, and, consequently, the first transversality condition is always satisfied at the equilibrium. As for the second transversality condition, $\lim _{t \rightarrow \infty}\left(e^{-\rho t} \mu_{h} h\right)=0$, to be satisfied it must be that

$$
\lim _{t \rightarrow \infty}\left(-\rho+\frac{\dot{\mu}_{h}}{\mu_{h}}+\frac{\dot{h}}{h}\right)<0 .
$$

From the first order conditions (A.5) and (A.7), and using (A.39), we obtain that

$$
\frac{\dot{\mu}_{h}}{\mu_{h}}=\rho-B
$$

Substituting $\frac{\dot{h}}{h}=B-\delta-\rho$ and taking into account that $\dot{\mu}_{h} / \mu_{h}$, we obtain that

$$
-(\delta+\rho)<0
$$

which is always equal to $-(\rho+\delta)$, and, consequently, the second transversality condition is always satisfied at the equilibrium. 